\title{
A Comparison of Clinical and Radiological Parameters in the Evaluation of Molar Furcation Involvement in Periodontitis
}

\section{Usporedba kliničkih i radioloških parametara u procjeni zahvaćenosti furkacije molara kod parodontitisa}

\author{
${ }^{1}$ Dental Office Michael Wolf and Colleagues, Patrickstrasse 2, 65191 Wiesbaden \\ Ordinacija dentalne medicine Michaela Wolfa i kolega, Patrickstrasse 2, 65191 Wiesbaden \\ 2 Department of Periodontology, School of Dental Medicine, University of Zagreb, and Clinical Department of Periodontology, Clinical Hospital \\ Center \\ Zavod za parodontologiju Stomatološkog fakulteta Sveučilišta u Zagrebu \\ ${ }^{3}$ Department of Periodontology, Department of operative Dentistry and Periodontology, University Medical Center Mainz, Germany. \\ Poliklinika za parodontologiju i restaurativnu stomatologiju Sveučilišnoga medicinskog centra u Mainzu
}

\begin{abstract}
Objective: The aim of this study was to compare clinical, intra-surgical, 2D (panoramic) and 3D (CBCT)-based parameters in assessing molar furcation involvement (FI). Materials and Methods: Six patients with generalized periodontitis Stage II to IV, Grade B and C who were scheduled for the periodontal flap surgical treatment were recruited in the study. In total, 38 molar teeth with 93 furcation sites were analysed. All subjects had comprehensive periodontal examination, which included an assessment of molar Fl using Naber's probe according to modified Glickman's classification. Periodontal surgery was performed in patients with at least one maxillary molar with probing depth of $\geq 6 \mathrm{~mm}$. This probing demonstrated lower grade of Fl compared with intra-surgical findings. Results: Periodontal probing, intra-surgical measurement and measurements based on CBCT significantly correlated with each other regarding the assessment of $\mathrm{Fl}$, with $\mathrm{r}$ values ranging between 0.81 to 1.00 $(p<0.01)$. The correlation of panoramic radiograph with periodontal probing was 0.49 , with CBCT 0.39 and with intra-surgical measurements 0.36 . The results showed an excellent agreement and higher accuracy between intra-surgical measurements and CBCT (0.96), in contrast to clinical examination and panoramic radiography- 0.87 and 0.63 respectively. Different clinical and radiological modalities showed a correlation among each other. They are accurate and have their own benefits, which makes (renders) them useful in establishing periodontal diagnosis and treatment planning. Conclusion: However, CBCT offers significant advantages including excellent agreement and higher accuracy and can be used as justified as excellent diagnostic tool in detecting and locating FI to provide a more reliable diagnosis and basis for treatment decisions.
\end{abstract}

Received: June 23, 2019

Accepted: November 15, 2019

Address for correspondence

Sanja Komšić, DMD

Dental Office Michael Wolf and

Colleagues,

Patrickstrasse 2, 65191 Wiesbaden,

Germany

komsic.sanja@gmail.com

Key words

Furcation Defects; Molar; Periodontitis; Periodontal Probing

\section{Introduction}

According to American Academy of Periodontology, a furcation involvement is a condition in which periodontitis is affecting root trunk causing resorption of bone into the bior trifurcation area of a multi-rooted tooth (1). The extent of the defect and the position of marginal tissue in its relationship to the FI provide relevant clinical information for more accurate and reliable diagnosis and predictable prognosis, by helping to select an adequate treatment option. Furcation involvement is among other factors (clinical attachment loss, probing depth, tooth mobility) an important guide in clinical prognosis and therapeutic decisions (2). Therapy of FI is many times based on clinically identified extent of the involvement (3). The grade of FI contributes significantly to the prognosis of the tooth at following periodontal treatment and during the maintenance therapy (4). The treatment of
Uvod

Prema Američkoj akademiji za parodontologiju, zahvaćenost furkacije jest stanje koje nastaje kada parodontitis zahvati korijen zuba i uzrokuje resorpciju kosti u bifurkacijskom ili trifurkacijskom području višekorijenskoga zuba (1). Opseg oštećenja i položaj marginalnog tkiva u odnosu prema furkaciji daju relevantne kliničke informacije prijeko potrebne za precizniju i pouzdaniju dijagnozu i predvidivu prognozu te pomažu u odabiru odgovarajućeg liječenja. Zahvaćenost furkacije je, između ostalih čimbenika (gubitak pričvrstka, dubina sondiranja, pomičnost zuba), važan vodič u kliničkoj prognozi i donošenju terapijskih odluka (2). Terapija zahvaćene furkacije često se temelji na klinički utvrđenom opsegu njezine zahvaćenosti (3). Stupanj njezine zahvaćenosti važan je čimbenik u donošenju prognoze nakon provedenog parodontnog liječenja te tijekom terapije održavanja (4). Li- 
the cases with FI presents a great challenge since the furcation is an area of specific anatomic morphology that may be challenging to debride with standard periodontal instrumentation (5-8) and are difficult to reach by standard oral hygiene measures. $81 \%$ of furcations have diameter entrances $<1,00 \mathrm{~mm}$ and $58 \%<0,75 \mathrm{~mm}(6)$. Narrow entrances, presence of ridges, convexities and concavities often do not allow for adequate instrumentation or complete plaque removal by patient (9). The scaling and root planing in the furcation area proved to be more effective when the treatment is performed surgically, emphasizing the importance of adequate clinical diagnosis (6-7). However, physical access, morphological variations and measurement errors can limit the correct assessment of FI (10-12), thus leading to alteration of treatment plan and adding unanticipated treatment costs (13-14).

Traditionally, the FI is assessed by utilizing both clinical and radiographic examinations. Clinical examination is performed with curved scaled Naber's probe and FI is categorized according to the one of the proposed classification systems. To describe the extent and features of the furcation defect, 1953. Glickman developed one of the first classification system, which is still today one of the most widely used classification systems for assessing FI (15):

Grade I is the incipient or early involvement. There is a supra-alveolar pocket with minimal bone loss in the furcation area. A radiographic change is not detectable, while the probe penetration is clinically absent.

Grade II includes cases with bone destruction on one or more aspects of the furcation. However, some portions of the soft and hard tissues remain intact, which does not allow complete penetration of the probe into the furcation area. Radiographic changes may or may not be present.

Grade III means that the inter-radicular bone is not present, but the orifices of furcations are covered with soft tissue only. The furcation entrance is not clinically visible, although there is a through- and- through- lesion present. Usually, this destruction will appear as a radiolucency between the roots, especially in the mandible.

Grade IV is the most severe involvement with a complete destruction of the inter-radicular bone in the furcation area. The furcation opening is clinically visible because the soft tissues also receded more apically. The radiographic image basically corresponds to the grade III findings. The imaging of periodontal structures complements the clinical examination and can be achieved through extraoral panoramic radiographs, intraoral periapical and bite-wing radiographs (16). However, 2D radiographs are limited due to projection geometry, since they allow only two-dimensional presentation of three-dimensional periodontal structures.

The standardized clinical protocol used in diagnostics of periodontitis was described for the first time more than 50 years ago and has not changed much since then (17), The advancements in dento-alveolar imaging could overcome the limitations of conventional intraoral radiographs providing the true three-dimensional imaging by using the cone beam computed tomography (CBCT). CBCT generates $3 \mathrm{D}$ volumetric images and it has been commonly used in dentistry. All CBCT units provide multi-planar axial, coronal and ječenje zahvaćene furkacije velik je klinički izazov zato što je furkacija područje specifične anatomske morfologije koje je teško dostupno standardnim parodontnim instrumentima (5 - 8) te standardnim oralno-higijenskim mjerama. $81 \%$ furkacija ima promjer ulaza $<1,00 \mathrm{~mm}$ i $58 \%<0,75 \mathrm{~mm}$ (6). Uski ulazi, greben, konveksitet i konkavitet često ne dopuštaju odgovarajuću instrumentaciju ili pacijent ne može potpuno ukloniti plak (9). Struganje i poliranje korijena u području fukacije pokazalo se učinkovitijim kada se liječenje obavlja kirurški, ističući važnost odgovarajuće kliničke dijagnoze (67). No fizički pristup, morfološke varijacije i pogreške u mjerenju mogu ograničiti ispravnu procjenu zahvaćenosti furkacije $(10-12)$, što rezultira promjenom plana liječenja i neočekivano povećava troškove liječenja $(13-14)$.

Zahvaćenost furkacije uobičajeno se procjenjuje kliničkim i radiografskim pregledom. Klinički pregled obavlja se Nabersovom zakrivljenom i graduiranom sondom, a zahvaćenost se može klasificirati prema jednom od predloženih klasifikacijskih sustava. Da bi opisao opseg i obilježja furkacije, Glickman je 1953. predložio jedan od prvih klasifikacijskih sustava koji je i danas među najčešće korištenima za procjenu zahvaćenosti furkacije (15):

Prvi razred početna je ili rana lezija. Postoji supraalveolarni džep s minimalnim gubitkom kosti u području furkacije. Radiografska promjena ne može se uočiti, a penetracija sonde klinički je odsutna.

Drugi razred uključuje slučajeve koštane destrukcije na jednom ili više ulaza u furkaciju. No dio mekih i tvrdih tkiva ostaje netaknut, što ne dopušta potpuni prodor sonde u područje fukacije. Promjena na radiogramu može biti, ali i ne mora.

Treći razred karakterizira gubitak interradikularne kosti, pri čemu su ulazi u furkaciju prekriveni samo mekim tkivom. Ulaz nije klinički vidljiv, iako se u kosti nalazi potpuno prohodna lezija. Destrukcija kosti uobičajeno se uočava kao radiolucencija između korijena zuba, posebno u mandibuli.

Četvrti razred najviši je stupanj zahvaćenosti furkacije, a obilježava ga potpuna destrukcija interradikularne kosti u području furkacije. Ulaz u furkaciju je klinički vidljiv jer su se i meka tkiva povukla prema apikalno. Radiografska slika u osnovi odgovara nalazima III. razreda. Radiografsko snimanje parodontnih struktura nadopunjuje klinički pregled i može se postići ekstraoralnim panoramskim radiogramima, intraoralnim periapikalnim radiogramima i zagriznim snimkama (16). No 2D radiografija ograničena je zbog projekcijske geometrije jer omogućuje samo dvodimenzionalno prikazivanje trodimenzionalnih parodontnih struktura.

Standardizirani klinički protokol kojim se koristimo u dijagnostici parodontitisa opisan je prvi put prije više od 50 godina i od tada se nije znatnije promijenio (17). Napredak u dento-alveolarnom snimanju mogao bi prevladati ograničenja konvencionalnih intraoralnih radiograma pružajući realno trodimenzionalno snimanje $s$ pomoću računalne tomografije konusnih zraka (CBCT). CBCT stvara $3 \mathrm{D}$ volumetrijske slike i već se često primjenjuje u stomatologiji. Sve CBCT jedinice nude rekonstruirane multiplanarne aksijalne, koronalne i sagitalne snimke bez uvećanja (18). Za razliku od 2D intraoralne radiografije i parodontnog sondiranja, 3D 
sagittal reconstructed images without magnification (18). In contrast to 2D intraoral radiographs and periodontal probing, 3D CBCT imaging was found to be more effective in evaluating periodontal structures. CBCT images have shown better potential for detecting periodontal bone defects in all directions compared with periapical radiographs (19). CBCT imaging is as accurate as clinical measurements with a periodontal probe and as reliable as intraoral radiographs for interproximal areas. Considering all numerous advantages which $\mathrm{CBCT}$ offers to provide accurate diagnosis, it is currently being considered as a superior diagnostic tool for various applications in periodontology (20). Due to high accuracy and various advantages (low radiation exposure, rapidity of scan time, reduced equipment costs), CBCT provides benefits in periodontal diagnostics, especially for advanced and complex periodontal disease including detailed information regarding the amount of bone loss, involvement of furcation, type of defects and their dimensions. Additionally, it is helpful in determining more accurate prognosis for each tooth by allowing $3 \mathrm{D}$ analysis of the surrounding bone, which influences the decision making process in periodontology, especially for periodontal regeneration procedures $(21,22)$. According to current available evidence, American Academy of Periodontology has stated that a 2D full-mouth radiograph combined with clinical periodontal probing remain the gold standard for a comprehensive evaluation of periodontal structures (23). However, experts on the best evidence consensus panel identified several scenarios where addition of CBCT imaging would be useful, including the scenario in which an advanced FI has been diagnosed (23). Although there are several in vivo and in vitro studies in assessing the accuracy of CBCT in the measurement of periodontal bone defects, there are just two studies that have investigated the efficacy of CBCT in diagnosing FI by comparing its result to intrasurgical assessment $(24,25)$. In both studies CBCT images demonstrated a high accuracy in evaluating the loss of periodontal tissue and classifying the degree of FI. The aim of this study was to evaluate (compare and correlate) clinical, intrasurgical, 2D (panoramic) und 3D (CBCT)-based parameters in assessing molar FI.

\section{Subjects and Methods}

Six patients with generalized periodontitis Stage II to IV, Grade B and C who were scheduled for the periodontal flap surgical treatment were recruited in the study. The study was approved by the Ethics Committee of University of Zagreb. Inclusive criteria were: completion of initial periodontal nonsurgical therapy, the presence of at least 15 teeth, at least 2 interproximal areas with a loss of attachment of $\geq 4 \mathrm{~mm}$ or at least 2 interproximal areas with pockets depth $\geq 5 \mathrm{~mm}$, but not on the same tooth, criteria for periodontitis in at least $30 \%$ of the teeth present (generalized periodontitis), optimal oral hygiene, FMPS and FMBS $<20 \%$. The initial therapy, including oral hygiene instruction and motivation, scaling and root planing and occlusal adjustment were performed and re-evaluations were scheduled following 3 and 6 months. After completion of initial non-surgical periodontal therapy, snimanje CBCT-om učinkovitije je u procjeni parodontnih struktura. CBCT snimke pokazuju veće mogućnosti dijagnosticiranja parodontnih koštanih defekata u svim smjerovima u usporedbi s periapikalnim radiografima (19). Snimanje CBCT-om jednako je precizno kao kliničko mjerenje parodontnom sondom i jednako pouzdano kao i intraoralni radiogrami za interproksimalna područja. S obzirom na mnogobrojne prednosti CBCT-a u postavljanju precizne dijagnoze, trenutačno se smatra superiornim dijagnostičkim sredstvom široke primjene u parodontologiji (20). Zbog velike preciznosti i različitih prednosti (niska izloženost zračenju, kratko vrijeme skeniranja, smanjeni troškovi opreme), CBCT je itekako koristan u parodontološkoj dijagnostici, posebno kad je riječ o napredovalim i kompleksnim slučajevima, uključujući i detaljne informacije o stupnju gubitka kosti, zahvaćenosti furkacije, vrsti resorpcije i njezinim dimenzijama. Uz to, koristan je u postavljanju preciznije prognoze pojedinačnih zuba jer omogućuje 3D analizu okolne kosti koja utječe na proces donošenja odluka u parodontologiji, posebno u postupcima vođene regeneracije tkiva $(21,22)$. Prema trenutačno dostupnim dokazima, Američka akademija za parodontologiju navodi da 2D rendgenska snimka svih zuba (status), u kombinaciji s kliničkim parodontnim sondiranjem, ostaje zlatni standard za sveobuhvatnu procjenu struktura parodonta (23). No vodeći su stručnjaci konsenzus panela zasnovanih na dokazima identificirali nekoliko scenarija u kojima bi primjena CBCT-a bila klinički korisna, uključujući i slučajeve kada je dijagnosticirana uznapredovala zahvaćenost furkacije (23). Iako postoji nekoliko studija in vivo i in vitro o procjeni točnosti CBCT-a u mjerenju parodontnih koštanih defekata, autori samo dviju studija ispitivali su učinkovitost CBCT-a u dijagnosticiranju zahvaćenosti furkacije $\mathrm{i}$ to usporedbom radiološkog s intraoperativnim mjerenjima $(24,25)$. U objema studijama CBCT snimke pokazale su visoku točnost u procjeni gubitka tkiva parodonta i u klasificiranju stupnja zahvaćenosti furkacije. Cilj ove studije bio je procijeniti (usporediti i korelirati) kliničke, intraoperativne, 2D (panoramske) i 3D (CBCT) parametre u procjeni zahvaćenosti furkacije molara.

\section{Ispitanici i metode}

U studiju je bilo uključeno šest pacijenata s generaliziranim parodontitisom od II. do IV. stadija B i C razreda određenih za kiruršku parodontnu terapiju. Studiju je odobrilo Etičko povjerenstvo Sveučilišta u Zagrebu. Kriteriji za sudjelovanje bili su završena inicijalna parodontna nekirurška terapija, najmanje 15 zuba u čeljusti, najmanje dva interproksimalna područja $s$ gubitkom kosti od $\geq 4 \mathrm{~mm}$ ili barem dva interproksimalna područja $s$ dubinom džepa od $\geq 5 \mathrm{~mm}$, ali ne na istom zubu, kriteriji za parodontitis kod najmanje 30 $\%$ zuba (generalizirani parodontitis), optimalna oralna higijena te FMPS i FMBS $<20 \%$. Završena je inicijalna terapija, uključujući i upute u oralnoj higijeni, motivacija, struganje i poliranje korijena te okluzijsko prilagođavanje, a reevaluacija je učinjena nakon tri i šest mjeseci. Nakon završetka inicijalne parodontne terapije pacijenti su potpisali suglasnost prije su- 
a written consent was taken from the patients prior to participation in the study. Periodontal surgery was performed only in patients with at least one maxillary molar with probing pocket depth of $\geq 6 \mathrm{~mm}$.

All subjects underwent a comprehensive periodontal evaluation, which included an assessment of molar FI using $\mathrm{Na}$ ber's probe according to modified Glickman's classification (26): Class I, horizontal bone loss $<2 \mathrm{~mm}$ into the furcation; Class II, horizontal bone loss deeper than $2 \mathrm{~mm}$ but less than $6 \mathrm{~mm}$ into the furcation; Class III, extensive horizontal bone loss with a through-and-through lesion.

The panoramic dental radiographs were taken using Sirona Orthophos XG X-ray unit (Sirona Dental Systems GmbH, Fabrikstrasse 5, 64625 Bensheim, Germany) set at $64 \mathrm{kV}$ and $8 \mathrm{~mA}$ with exposition time 14,1 s. The presence of triangular radiolucency at the furcation area was radiographic sign for FI, which was recorded as present or absent.

CBCT scans were obtained with Planmeca ProMax 3D CBCT (Planmeca Oy, Asentajankatu 6, 00880 Helsinki, Finland) with 90kV, 10mA, FOV 1001x1001x999mm, 360 rotation, exposition time 18,071s, voxel size $200 \mu \mathrm{m}$. Third quartile of dose area product (DAP) was $1555.9 \mathrm{mGy} \mathrm{x} \mathrm{cm}$. CBCT images were obtained using Romexis Viewer Planmeca 3.8.3.R. (Planmeca Oy, Asentajankatu 6, 00880 Helsinki, Finland), generated in the digital imaging and communications in medicine (DICOM) format and analyzed by axial and sagittal reconstructions with cutting interval of $1 \mathrm{~mm}$. The FI was presented as a trabecular bone resorption at the furcation area on both sagittal and axial view. The depth was determined on the axial slice as a distance from a line that was drawn tangentially to the neighboring root surfaces to the deepest point of bone loss.

After the CBCT scan, periodontal flap surgery was performed. Following administration of local anesthesia, a full thickness mucoperiostal flap was raised. Direct clinical intrasurgical measurements were made prior to complete scaling and root planing. Since the measurements in Glickman's classification are made in presence of soft tissues, the intra-surgical FI assessments were performed according to modified Glickman's classification (26). FI intra-surgically and on CBCT were assessed at three sites (buccal, mesio-palatal and disto-palatal) of maxillary molars and two sites (buccal and lingual) of mandibular molars using Naber's probe. In order to eliminate inter-examiner discrepancies the same investigator performed all clinical and radiological measurements in all patients.

True-positives (TP - the number of cases correctly identified as FI), false-positives (FP - the number of cases incorrectly identified as FI), true-negatives (TN- the number of cases correctly identified as absence of FI) and false-negatives (FN - the number of cases incorrectly identified as absence of FI) were determined using intra-surgical findings as the gold standard. This evaluation of FI was assessed using dichotomous scale (present/absent) and according to modified Glickman's scale. Test characteristics were calculated (sensitivity, specificity, positive predictive value -PPV, negative predictive value-NPV, diagnostic accuracy -ACC, false discovery rate -FDV, diagnostic odds ratio -DOR) using following formulas: djelovanja u studiji. Parodontna kirurška terapija provedena je samo kod pacijenata s najmanje jednim maksilarnim molarom dubine sondiranja $\geq 6 \mathrm{~mm}$.

Svi ispitanici obavili su sveobuhvatnu parodontnu evaluaciju koja je uključivala procjenu zahvaćenosti furkacije s pomoću Nabersove sonde prema modificiranoj Glickmanovoj klasifikaciji (26): prvi razred - horizontalni gubitak kosti od $<2 \mathrm{~mm}$ u furkaciji; drugi razred - horizontalni gubitak kosti dublji od $2 \mathrm{~mm}$, ali manji od $6 \mathrm{~mm}$ u furkaciji; treći razred ekstenzivni horizontalni gubitak kosti s prohodnom lezijom.

Panoramske radiografske snimke učinjene su rendgenskom jedinicom Sirona Orthophos (Sirona Dental Systems GmbH, Fabrikstrasse 5, 64625 Bensheim, Njemačka) postavljenom na $64 \mathrm{kV}$ i $8 \mathrm{~mA}$ s vremenom ekspozicije od 14,1 sekunde. Trokutasta radiolucencija u području furkacije bio je radiografski znak za zahvaćenost furkacije koji je zabilježen kao prisutan ili odsutan.

CBCT snimke dobivene su s pomoću uređaja Planmeca ProMax 3D CBCT (Planmeca Oy, Asentajankatu 6, 00880 Helsinki, Finska) s 90 kV, 10 mA, FOV 1001 x 1001 x 999 $\mathrm{mm}$, rotacijom od $360^{\circ}$, s vremenom ekspozicije od 18,071 sekunde i veličinom voksela od $200 \mu \mathrm{m}$. Treći kvartil proizvo-

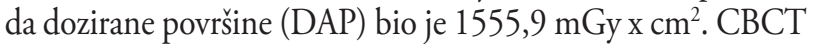
slike dobivene su uređajem Omexis Viewer Planmeca 3.8.3.R. (Planmeca Oy, Asentajankatu 6, 00880 Helsinki, Finska) te generirane $\mathrm{u}$ formatu digitalnog prikazivanja i komunikacije u medicini (DICOM-a) i analizirane u aksijalnim i sagitalnim rekonstrukcijama s intervalom reza od 1 milimetra. Zahvaćenost furkacije zabilježena je kao trabekularna resorpcija kosti u području furkacije, u sagitalnom i aksijalnom presjeku. Dubina je određena na aksijalnom presjeku kao udaljenost od linije koja se tangencijalno povukla do susjednih korijenskih površina do najdublje točke gubitka kosti.

Nakon CBCT snimke obavljena je parodontna kirurška terapija. Nakon aplikacije lokalne anestezije, odignut je mukoperiostalni režanj pune debljine. Učinjeno je direktno kliničko intraoperativno mjerenje dubine defekta prije struganja i poliranja korijena. Kako su mjerenja u Glickmanovoj klasifikaciji učinjena u prisutnosti mekih tkiva, intraoperativne procjene zahvaćenosti furkacije obavljene su prema modificiranoj Glickmanovoj klasifikaciji (26). Zahvaćenost furkacije intraoperativno i na snimkama CBCT-a procijenjena je na trima mjestima (bukalno, meziopalatinalno i distopalatinalno) maksilarnih molara i dvama mjestima (bukalno i lingvalno) mandibularnih molara s pomoću Nabersove sonde. Kako bi se otklonila nedosljednost ispitivača, isti je istraživač na svim ispitanicima obavio sva klinička i radiološka mjerenja.

Stvarno pozitivni (TP - broj slučajeva ispravno identificiranih kao zahvaćenost furkacije), lažno pozitivni (FP - broj slučajeva pogrešno identificiranih kao zahvaćenost furkacije), stvarno negativni (TN - broj slučajeva ispravno identificiranih kao nepostojanje zahvaćenosti furkacije) i lažno negativni (FN - broj slučajeva pogrešno identificiranih kao odsutnost zahvaćenosti furkacije) određeni su korištenjem intraoperativnih nalaza kao zlatnog standarda. Ta evaluacija zahvaćenosti furkacije procijenjena je korištenjem dihotomne ljestvice (prisutna/odsutna) i prema modificiranoj Glickmanovoj ljestvici. Zatim su izračunate karakteristike testa (osjetljivost, 
Sensitivity $=\mathrm{TP} /(\mathrm{TP}+\mathrm{FN})$

Specificity $=\mathrm{TN} /(\mathrm{TN}+\mathrm{FP})$

$\mathrm{PPV}=\mathrm{TP} /(\mathrm{TP}+\mathrm{FP})$

$\mathrm{NPV}=\mathrm{TN} /(\mathrm{TN}+\mathrm{FN})$

$\mathrm{ACC}=(\mathrm{TN}+\mathrm{TP}) /(\mathrm{TN}+\mathrm{TP}+\mathrm{FN}+\mathrm{FP})$.

$\mathrm{FDR}=\mathrm{FP} / \mathrm{TP}$

$\mathrm{DOR}=(\mathrm{TP} / \mathrm{FP}) /(\mathrm{FN} / \mathrm{TN})$

The sample size was calculated using power analysis before the initiation of the study, assuming a difference of $<5 \%$ between radiographic and surgical measurements and using the formula $(\mathrm{z} \alpha)^{2} \times(\mathrm{s})^{2} /(\mathrm{d})^{2}$. The collected data were subjected to statistical analysis using SPSS software for Windows (SPSS Inc, Chicago, IL). The Kappa statistics was used to determine intra-observer agreement. The kappa values were interpreted as recommended by Landis and Koch and adapted by Altman: $\mathrm{k} \leq 0.20$ poor, $0.21-0.40$ fair, $0.41-0.60$ moderate, $0.61-0.80$ good, $0.81-1.00$ very good (27). The Pearson's correlation test was used to correlate the measurements performed clinically and radiologically. The statistical significance was set at $\mathrm{p}<0.05$. Accuracy, sensitivity, specificity, positive and negative predictive values and accuracy were calculated with the McNemar $\chi^{2}$ test.

\section{Results}

The study was conducted on 6 patients: 2 were females, 4 males and an age range of $35-77$ with a mean age $53.50 \pm 14.80$. In total, 38 molar teeth with 93 furcation sites were analysed (9 maxillary first molars, 8 maxillary second molars, 10 mandibular first molars, 11 mandibular second molars). The kappa values for intra-observer agreement ranged between good and very good, as follows: 0.72 for periodontal probing, 0.81 for intra-surgical measurements and 0.85 for CBCT measurements.

The comparison of maxillary molar assessment showed that probing generally demonstrated lower grade of FI compared with intra-surgical findings. For 5,88\% of cases periodontal probing could not detect bone loss in class III furcations and also failed to detect any bone loss in class I furcations. On the contrary, $\mathrm{CBCT}$ showed high agreement with intra-surgical examination. The maxillary molar FI assessed by periodontal probing, panoramic radiograph and CBCT is illustrated in Table 1. A comparison of mandibular furcations revealed scenarios in which no FI was detected clinically, however $19,04 \%$ of cases were demonstrated to have some class of furcation involvement by intra-surgical findings. Similarly to maxillary molars, CBCT demonstrated high correlation with intra-surgical examination. The mandibular molar FI evaluated by clinical examination, intra-surgical and CBCT interpretation is shown in Table 2.

The Spearman's correlation demonstrated that periodontal probing, intra-surgical measurement and measurements specifičnost, pozitivna prediktivna vrijednost - PPV, negativna prediktivna vrijednost - NPV, dijagnostička točnost ACC, stopa lažnog otkrivanja - FDV, omjer dijagnostičkih izgleda - DOR) koristeći se sljedećom formulom:

osjetljivost $=\mathrm{TP} /(\mathrm{TP}+\mathrm{FN})$

specifičnost $=\mathrm{TN} /(\mathrm{TN}+\mathrm{FP})$

$\mathrm{PPV}=\mathrm{TP} /(\mathrm{TP}+\mathrm{FP})$

$\mathrm{NPV}=\mathrm{TN} /(\mathrm{TN}+\mathrm{FN})$

$\mathrm{ACC}=(\mathrm{TN}+\mathrm{TP}) /(\mathrm{TN}+\mathrm{TP}+\mathrm{FN}+\mathrm{FP})$.

$\mathrm{FDR}=\mathrm{FP} / \mathrm{TP}$

$\mathrm{DOR}=(\mathrm{TP} / \mathrm{FP}) /(\mathrm{FN} / \mathrm{TN})$

Veličina uzorka izračunata je korištenjem analize snage statističkoga testa (power analize) prije početka ispitivanja, pretpostavljajući razliku od $<5 \%$ između radiografskih i intraoperativnih mjerenja i korištenjem formule $(\mathrm{z} \alpha)^{2} \times(\mathrm{s})^{2} /$ $(\mathrm{d})^{2}$. Prikupljeni podatci statistički su analizirani SPSS softverom za Windowse (SPSS Inc, Chicago, IL). Kappa test korišten je za utvrđivanje podudarnosti ispitivača. Njegove vrijednosti interpretirane su prema preporukama Landisa i Kocha prilagođenima prema Altmanu: $\mathrm{k} \leq 0,20$ slaba, 0,21 - 0,40 dovoljna, 0,41 - 0,60 umjerena, 0,61 - 0,80 dobra, $0,81-1,00$ vrlo dobra podudarnost (27). Pearsonov korelacijski test korišten je za povezivanje mjerenja obavljenih klinički i radiološki. Statistička značajnost postavljena je na $\mathrm{p}<$ 0,05 . Preciznost, osjetljivost, specifičnost te pozitivne i negativne prediktivne vrijednosti i točnost izračunati su s pomoću testa McNemar $\chi 2$.

\section{Rezultati}

Studija je provedena na šestero pacijenata - na dvjema ženama i na četvorici muškarca u dobi od 35 do 77 godina (prosjek 53,50 $\pm 14,80$ ). Ukupno je analizirano 38 molara s 93 mjesta furkacije ( 9 prvih maksilarnih molara, 8 drugih maksilarnih molara, 10 prvih mandibularnih molara, 11 drugih mandibularnih molara). Vrijednosti kappa testa kretale su se između dobroga i vrlo dobroga $-0,72$ za parodontno sondiranje, 0,81 za intraoperativno mjerenje i 0,85 za CBCT mjerenja.

Usporedba procjene maksilarnih molara pokazala je da sondiranje općenito prikazuje niži stupanj zahvaćenosti furkacije u usporedbi s intraoperativnim nalazima. U 5,88 \% slučajeva parodontno sondiranje nije moglo detektirati gubitak kosti u području furkacije III. razreda, a također nije uspjelo otkriti gubitak kosti u furkacijama I. razreda. Suprotno tomu, CBCT snimke pokazale su visoku podudarnost $s$ intraoperativnim nalazom. Zahvaćenost furkacije maksilarnih molara procijenjena parodontnim sondiranjem, panoramskim radiogramom i CBCT-om prikazana je u tablici 1. Usporedba procjene mandibularnih molara otkrila je slučajeve kada klinički nije otkrivena zahvaćenost furkacije, a u 19,04 \% slučajeva pokazao se pozitivnim intraoperativni nalaz. Slično kao kod maksilarnih molara, CBCT je pokazao visoku podudarnost s intraoperativnim nalazima. Zahvaćenost furkacije mandibularnih molara procijenjena parodontnim sondiranjem, panoramskim radiogramom i CBCT-om nalazi se u tablici 2.

Spearmanova korelacija pokazala je da parodontno sondiranje, intraoperativno mjerenje i mjerenje na CBCT-u zna- 
Table 1 Maxillary molar Fl of evaluated sites assessed by periodontal probing, intrasurgical measurement and measured by CBCT.

Tablica 1. Zahvaćenost furkacije maksilarnih molara procijenjena parodontnim sondiranjem, panoramskim radiogramom i CBCT-om

\begin{tabular}{|c|c|c|c|c|c|c|c|c|c|}
\hline \multirow{2}{*}{$\begin{array}{l}\text { Modified Glickman's } \\
\text { Classification } \\
\text { - Modificirana } \\
\text { Glickmanova } \\
\text { klasifikacija }\end{array}$} & \multicolumn{3}{|c|}{ Buccal $\bullet$ Bukalno } & \multicolumn{3}{|c|}{ Mesial palatal $\bullet$ Meziopalatinalno } & \multicolumn{3}{|c|}{ Distal palatal $\bullet$ Distopalatinalno } \\
\hline & $\begin{array}{c}\text { Periodontal } \\
\text { probing } \\
\text { Sondiranje }\end{array}$ & $\begin{array}{c}\text { Intrasurgical } \\
\text { measurement } \\
\text { Intraoperativno } \\
\text { mjerenje }\end{array}$ & СВCT & $\begin{array}{l}\text { Periodontal } \\
\text { probing } \\
\text { Sondiranje }\end{array}$ & $\begin{array}{c}\text { Intrasurgical } \\
\text { measurement } \\
\text { Intraoperativno } \\
\text { mjerenje }\end{array}$ & CBCT & $\begin{array}{c}\text { Periodontal } \\
\text { probing } \\
\text { Sondiranje }\end{array}$ & $\begin{array}{c}\text { Intrasurgical } \\
\text { measurement } \\
\text { Intraoperativno } \\
\text { mjerenje }\end{array}$ & CBCT \\
\hline $\begin{array}{c}\text { Not present } \\
\text { prisutna }\end{array}$ & $58.82 \%$ & $52.94 \%$ & $52.94 \%$ & $52.38 \%$ & $58.82 \%$ & $58.82 \%$ & $64.71 \%$ & $52.94 \%$ & $58.82 \%$ \\
\hline Class I • Razred I. & $35.29 \%$ & $29.41 \%$ & $29.41 \%$ & $23.81 \%$ & $29.41 \%$ & $29.41 \%$ & $29.41 \%$ & $35.29 \%$ & $29.41 \%$ \\
\hline Class II • Razred II. & $5.88 \%$ & $11.76 \%$ & $11.76 \%$ & $4.76 \%$ & $5.88 \%$ & $5.88 \%$ & $5.88 \%$ & $5.88 \%$ & $5.88 \%$ \\
\hline Class III • Razred III. & 0 & $5.88 \%$ & $5.88 \%$ & 0 & $5.88 \%$ & $5.88 \%$ & 0 & $5.88 \%$ & $5.88 \%$ \\
\hline
\end{tabular}

Table 2. Mandibular molar Fl of evaluated sites assessed by periodontal probing, intrasurgical measurement and measured by CBCT.

Tablica 2. Zahvaćenost furkacije mandibularnih molara procijenjena parodontnim sondiranjem, panoramskim radiogramom i CBCT-om

\begin{tabular}{|c|c|c|c|c|c|c|}
\hline \multirow[b]{2}{*}{$\begin{array}{c}\text { Modified Glickman's } \\
\text { Classification • Modificirana } \\
\text { Glickmanova klasifikacija }\end{array}$} & \multicolumn{3}{|c|}{ Buccal $\bullet$ Bukalno } & \multicolumn{3}{|c|}{ Lingual $\bullet$ Lingvalno } \\
\hline & $\begin{array}{c}\text { Periodontal } \\
\text { probing } \\
\text { Sondiranje }\end{array}$ & $\begin{array}{c}\text { Intrasurgical } \\
\text { measurement } \\
\text { Intraoperativno } \\
\text { mjerenje }\end{array}$ & СВCT & $\begin{array}{c}\text { Periodontal } \\
\text { probing } \\
\text { Sondiranje }\end{array}$ & $\begin{array}{c}\text { Intrasurgical } \\
\text { measurement } \\
\text { Intraoperativno } \\
\text { mjerenje }\end{array}$ & СBCT \\
\hline Not present $\bullet$ Nije prisutna & $61.90 \%$ & $42.86 \%$ & $42.86 \%$ & $61.90 \%$ & $42.86 \%$ & $47.62 \%$ \\
\hline Class I • Razred I. & $23.81 \%$ & $38.10 \%$ & $38.10 \%$ & $28.57 \%$ & $42.86 \%$ & $38.10 \%$ \\
\hline Class II • Razred II. & $14.29 \%$ & $9.52 \%$ & $14.29 \%$ & $9.52 \%$ & $9.52 \%$ & $4.76 \%$ \\
\hline Class III • Razred III. & 0 & $9.52 \%$ & $4.76 \%$ & 0 & $4.76 \%$ & $9.52 \%$ \\
\hline
\end{tabular}

Table 3 Correlation coefficients of periodontal probing and CBCT-measurements with intrasurgical measurements in assessment of $\mathrm{FI}$ (correlation is significant at $\mathrm{p}<0.01$ ).

Tablica 3. Koeficijenti korelacije sondiranja i mjerenja CBCT-om komparirani s intraoperativnim mjerenjima u procjeni zahvaćenosti furkacije (korelacija je značajna pri $p<0,01$ )

\begin{tabular}{l|c|c|c} 
& $\begin{array}{c}\text { Periodontal probing/ } \\
\text { intra-surgical } \bullet \text { Sondiranje/ } \\
\text { intraoperativno }\end{array}$ & $\begin{array}{c}\text { CBCT/intra-surgical } \bullet \text { CBCT/ } \\
\text { intraoperativno }\end{array}$ & $\begin{array}{c}\text { Periodontal probing/CBCT } \text { Sondiranje/CBCT } \\
\text { Maxillary buccal } \bullet \text { Maksilarno bukalno }\end{array}$ \\
\hline $\begin{array}{l}\text { Maxillary mesial palatal } \bullet \\
\text { Maksilarno mezio-palatinalno }\end{array}$ & 0.91 & 1.00 & 0.91 \\
\hline $\begin{array}{l}\text { Maxillary distal palatal } \bullet \\
\text { Maksilarno distopalatinalno }\end{array}$ & 0.92 & 0.92 & 0.92 \\
\hline $\begin{array}{l}\text { Mandibular buccal } \bullet \\
\text { Mandibularno bukalno }\end{array}$ & 0.87 & 0.96 & 0.92 \\
\hline $\begin{array}{l}\text { Mandibular lingual } \bullet \\
\text { Mandibularno lingvalno }\end{array}$ & 0.83 & 0.98 & 0.85 \\
\hline
\end{tabular}

Table 4 Sensitivity, specificity, positive predictive value, negative predictive value, accuracy, false discovery rate and diagnostic odds ratio in detection of Fl by periodontal probing, panoramic radiograph and CBCT using intra-surgical findings as the gold standard.

Tablica 4. Senzitivnost, specifičnost, pozitivna prediktivna vrijednost, negativna prediktivna vrijednost, točnost, stopa lažnog otkrivanja i omjer dijagnostičkih izgleda u otkrivanju zahvaćenosti furkacije parodontnim sondiranjem, panoramskim radiogramom i CBCT-om koristeći se intraoperativnim nalazom kao zlatnim standardom

\begin{tabular}{|c|c|c|c|c|c|c|c|}
\hline & $\begin{array}{l}\text { Sensitivity • } \\
\text { Senzitivnost }\end{array}$ & $\begin{array}{l}\text { Specificity } \\
\text { Specifičnost }\end{array}$ & $\begin{array}{c}\text { Positive } \\
\text { predictive value } \\
(\text { PPV) } \\
\text { Pozitivna } \\
\text { prediktivna } \\
\text { vrijednost (PPV) }\end{array}$ & $\begin{array}{c}\text { Negative } \\
\text { predictive value } \\
(\mathrm{NPV}) \bullet \\
\text { Negativna } \\
\text { prediktivna } \\
\text { vrijednost (NPV) }\end{array}$ & $\begin{array}{l}\text { Accuracy } \\
\text { (ACC) } \\
\text { Točnost } \\
\text { (ACC) }\end{array}$ & $\begin{array}{c}\text { False discovery } \\
\text { rate (FDR) } \\
\text { Stopa lažnog } \\
\text { otkrivanja } \\
\text { (FDR) }\end{array}$ & $\begin{array}{l}\text { DOR (diagnostic } \\
\text { odds ratio) } \\
\bullet \text { Omjer } \\
\text { dijagnostičkih } \\
\text { izgleda (DOR) }\end{array}$ \\
\hline $\begin{array}{l}\text { Periodontal probing } \bullet \\
\text { Sondiranje }\end{array}$ & 0.74 & 1.00 & 1.00 & 0.79 & 0.87 & 0 & 0 \\
\hline $\begin{array}{l}\text { Panoramic radiograph } \\
(\mathrm{OPG}) \cdot \text { Panoramski } \\
\text { radiogram }(\mathrm{OPG})\end{array}$ & 0.31 & 0.95 & 0.88 & 0.57 & 0.63 & 0.13 & 8.53 \\
\hline СBCT & 0.93 & 1.00 & 1.00 & 0.93 & 0.96 & 0 & 0 \\
\hline
\end{tabular}


based on CBCT significantly correlated with each other in the assessment of FI, with $r$ values ranged between 0.81 to 1.00 ( $<<0.01$; Table 3). The largest agreement $(100 \%)$ was found in buccal maxillary sites between CBCT and intra-surgical measurement. The smallest agreement $(81 \%)$ was found in lingual mandibular molars, in which $19 \%$ of FI was detected using CBCT, although not clinically. The correlation of panoramic radiograph with periodontal probing was 0.49 , with $\mathrm{CBCT}$ 0.39, and with intra-surgical measurements it was 0.36 .

The results showed an excellent agreement and higher accuracy between intra-surgical measurements and CBCT (0.96), in contrast to clinical examination and panoramic radiography- 0.87 and 0.63 respectively (Table 4$)$. CBCT can be used as highly sensitive (0.93) and specific test (1.00) to accurately identify the FI when it is really present and to rule out the FI if it is not radiologically detectable. On the other hand, panoramic radiographs showed low sensitivity and high specificity, which means that these tests give a few false positive results but they are unable to identify the majority of the positive cases of FI (69\%). Periodontal probing showed generally satisfying sensitivity (0.74) and high specificity (1.00). Precision of periodontal probing and CBCT was higher $(\mathrm{PPV}=1.00)$ compared to panoramic radiographs $(\mathrm{PPV}=0.88)$. The false discovery rate and diagnostic odds ratio as useful indicators of test performance were not comparable, since the values by periodontal probing and $\mathrm{CBCT}$ were 0 , which can be attributed to a small sample size.

\section{Discussion}

Different diagnostic methods showed significant correlation among each other and the results confirmed the clinical relevance of $\mathrm{CBCT}$ in the $\mathrm{FI}$ assessment, since $\mathrm{CBCT}$ showed a strong agreement with the direct intra-surgical findings (the current "gold standard") in the detection of FI. Although all included patients were diagnosed with generalized periodontitis, more than half of them showed no FI based on the four evaluation methods (52.94-64.71\%).

Accuracy of clinical detection of FI is unpredictable, since it depends on many factors, such as: operator technique and experience (probe angulation, amount of force exerted, access), tooth position, inclination, presence of adjacent teeth, length of root trunk, root morphology, roots divergence and configuration of residual inter-radicular bone (28-29). The results of our study showed that periodontal probing of maxillary and mandibular molars generally underestimated the extent of FI, suggesting that clinical detection is unreliable and should be supplemented with radiographs (30-31). In many cases, the clinical measurement reflects the probing depth into the inflamed connective tissue, instead of the actual depth of the inter-radicular bony defect (32). The study of Graetz et al. demonstrated that determining the degree of FI by clinical probing was accurate in only $56 \%$ of assessed cases (33). In our study, the clinical detection identified the absence of FI, although the $5.88-11.77 \%$ of cases demonstrated bone loss intra-surgically and on CBCT images, thus indicating under-detection. Periodontal probing also čajno korelira u procjeni zahvaćenosti furkacije, $s \mathbf{r}$ vrijednostima u rasponu od 0,81 do 1,00 ( $<<0,01$; tablica 3.). Najveća podudarnost (100 \%) pronađena je na maksilarnim molarima bukalno između CBCT-a i intraoperativnog mjerenja. Najmanje podudaranje (81 \%) bilo je na mandibularnim molarima lingvalno - tu je $19 \%$ zahvaćenih furkacija otkriveno korištenjem CBCT-a, ali ne i klinički. Korelacija panoramskog radiograma s parodontnim sondiranjem iznosi 0,49, s CBCT-om 0,39 i s intraoperativnim mjerenjima 0,36.

Rezultati su pokazali odličnu podudarnost i veliku preciznost intraoperativnih mjerenja i CBCT-a $(0,96)$, za razliku od kliničkog pregleda i panoramske radiografije - 0,87 i 0,63 (tablica 4.). CBCT se može upotrebljavati kao visoko osjetljiv $(0,93)$ i specifičan test $(1,00)$ za precizno ustanovljavanje zahvaćenosti furkacije kada ona stvarno postoji te za njezino isključivanje u slučaju kad nije radiološki detektirana. S druge strane, panoramski radiogrami pokazali su nisku osjetljivost i visoku specifičnost, što znači da će ti testovi dati nekoliko lažno pozitivnih rezultata, ali ne mogu identificirati većinu pozitivnih slučajeva (69\%). Parodontno sondiranje pokazalo je općenito zadovoljavajuću osjetljivost $(0,74)$ i visoku specifičnost $(1,00)$. Preciznost parodontnog sondiranja i CBCT-a veća je $(\mathrm{PPV}=1,00)$ u usporedbi s panoramskim radiogramima (PPV $=0,88)$. Omjer lažne stope otkrivanja i dijagnostičkih izgleda, kao korisnih pokazatelja u ispitivanju, ne mogu se usporediti jer su vrijednosti dobivene parodontnim sondiranjem i CBCT-om bile 0 , što se može pripisati maloj veličini uzorka.

\section{Rasprava}

Različite dijagnostičke metode pokazale su značajnu uzajamnu korelaciju, a rezultati su potvrdili kliničku važnost CBCT-a u procjeni zahvaćenosti furkacije jer je taj uređaj pokazao snažnu korelaciju s izravnim intraoperativnim nalazima (trenutačni zlatni standard) u otkrivanju zahvaćenosti furkacije. Iako je kod svih pacijenata dijagnosticiran generalizirani parodontitis, u više od polovine njih nije ustanovljena zahvaćenost furkacije na osnovi četiriju metoda evaluacije (52,94-64,71\%).

Točnost kliničkog otkrivanja zahvaćenosti furkacije nepredvidiva je jer ovisi o mnogim čimbenicima kao što su tehnika i iskustvo operatera (angulacija sonde, količina primjenjene sile, pristup), položaj zuba, nagib, susjedni zubi, duljina korijena, morfologija korijena, divergencija korijena i konfiguracija preostale interradikularne kosti $(28-29)$. Rezultati naše studije pokazali su da parodontno sondiranje maksilarnih i mandibularnih molara uglavnom podcjenjuje opseg zahvaćenosti furkacije te sugerira da je kliničko otkrivanje nepouzdano i da ga treba nadopuniti radiogramima (30 -31). U mnogim slučajevima kliničko mjerenje odražava dubinu sonde u upalnom vezivnom tkivu, umjesto stvarne dubine interradikularnog gubitka kosti (32). Studija Graetza i suradnika pokazala je da je određivanje stupnja zahvaćenosti furkacije kliničkim sondiranjem bilo točno samo u $56 \%$ procijenjenih slučajeva (33). U našoj studiji kliničkim je pregledom utvrđeno nepostojanje zahvaćenosti furkacije, iako je od 5,88 do 11,77 \% slučajeva pokazalo gubitak kostiju in- 
failed in detecting class III furcations. On the contrary, clinical examination showed over-detection of class I furcations. The results are in accordance with findings from other studies that showed that clinical detection can easily lead to under- or over-estimation of FI $(28,34)$. The findings confirmed the necessity of supplementing clinical detection with radiographic examination, which is in accordance with the consensus in the literature $(26,27)$.

The results of our study showed that the correlation of panoramic radiograph (orthopantomogram) with other detection methods was low (0.36-0.49). Precision of panoramic radiograph was satisfactory $(\mathrm{PPV}=0.88)$. However, panoramic radiograph had low sensitivity $(0.31)$ and high specificity $(0.95)$ for FI detection, mainly due to intrinsic limitations of $2 \mathrm{D}$ imaging such as anatomic complexity (superimposition of palatal root at the furcation region, sinus tract extending into furcation) and angulation problems (12,35-37). The detectability of early stages of FI on 2D imaging is especially inconsistent and limited (38).

The correlation of CBCT with intra-surgical findings was very high: $0.92-1.00$ for maxillary molars and $0.94-0.98$ for mandibular molars. CBCT was able to detect significant bone loss in class III furcations (more than $6 \mathrm{~mm}$ ), when other methods failed. Sensitivity and negative predictive value of CBCT in FI detection was 0.93 and specificity and positive predictive value 1.00, which suggests that CBST is a valuable tool in detection of FI, thus offering significant advantage over conventional clinical and radiographic assessments. Although the direct intra-surgical exploration is the most accurate way of assessing the degree of FI (28), the invasiveness and difficulty of performing it, make this method often inapplicable. CBCT reveals precisely and accurately the alveolar bone resorption, infra-bony pockets and furcation defects (39) and since the accuracy in our study was 0.96, it can be concluded that CBCT is capable to generate reliable and precise radiographs in patients with generalized periodontitis making it an excellent adjunctive diagnostic tool in periodontal treatment planning, which is in accordance with findings from other authors $(28,29,34,40,41)$. The studies of Walter and Qiao showed that the $84 \%$ and $82.4 \%$ of CBCT data, respectively, were confirmed by intra-surgical findings and assessment of maxillary molar FI (38\%). The differences may be explained by the surgical protocol probably leading to a minor loss of periodontal tissues during instrumentation, and that is the reason why we performed the measurements prior to scaling and root planing with debridement. A CBCT analysis was performed on hard tissue defects only, while intra-surgical measurements did not include flap thickness in the furcation area. On the other hand, periodontal probing of horizontal FI was measuring the supracrestal attached tissue. Therefore, different measuring methods might explain a lower correlation of clinical and intra-surgical or CBCT measurements. Another explanation for errors that exist between $\mathrm{CBCT}$ and direct surgical measurements can lie in the fact that there were different accuracies of those measurements. Clinical measurements were only able to be performed to the nearest $0.5 \mathrm{~mm}$, whereas CBCT measurements can be made to the nearest $0.1 \mathrm{~mm}$. Walter suggested traoperativno i na CBCT snimkama, što upućuje na podcjenjivanje stupnja koštane resorpcije. Parodontno sondiranje također nije uspjelo detektirati zahvaćenosti furkacija III. razreda. Naprotiv, klinički je pregled pokazao prekomjerno otkrivanje zahvaćenosti furkacija I. klase. Rezultati su u skladu s nalazima u drugim studijama koji su pokazali da klinička detekcija lako može dovesti do podcijenjenosti ili precijenjenosti zahvaćenosti furkacije $(28,34)$. Nalazi su potvrdili da je prijeko potrebna dopuna kliničkog otkrivanja radiografskim pregledom, što je u skladu s konsenzusom iz literature $(26,27)$.

Rezultati naše studije pokazali su da je korelacija panoramskog radiograma (ortopantomograma) s drugim metodama otkrivanja niska $(0,36-0,49)$. Preciznost panoramske radiografije bila je zadovoljavajuća (PPV $=0,88$ ). No panoramski radiogram imao je nisku osjetljivost $(0,31)$ i visoku specifičnost $(0,95)$ za detekciju zahvaćenosti furkacije, uglavnom zbog intrinzičnih ograničenja 2D snimanja, kao što su anatomska složenost (superpozicija palatinalnog korijena u području furkacije, sinusni trakt koji se širi u furkaciju) i angulacija $(12,35$ - 37). Otkrivanje ranih faza zahvaćenosti furkacije na 2D snimci posebno je nedosljedno i ograničeno (38).

Korelacija CBCT-a s intraoperativnim nalazima vrlo je visoka - od 0,92 do 1,00 za maksilarne molare i od 0,94 do 0,98 za mandibularne molare. CBCT je uspio detektirati znatan gubitak kosti u furkacijama III. razreda (više od 6 $\mathrm{mm}$ ), kada se to nije uspjelo drugim metodama. Osjetljivost i negativna prediktivna vrijednost CBCT-a u otkrivanju zahvaćenosti furkacije jest 0,93 , a specifičnost i pozitivna prediktivna vrijednost 1,00 , što sugerira da je CBST vrijedan uređaj u otkrivanju zahvaćenosti furkacije pa omogućuje značajnu prednost u usporedbi s klasičnim kliničkim i radiografskim metodama. Iako je direktno intraoperativno mjerenje najtočniji način procjene stupnja zahvaćenosti furkacije (28), invazivnost i poteškoće u njegovu obavljanju čine tu metodu često neprihvatljivom. CBCT otkriva precizno i pouzdano resorpciju alveolarne kosti, infrakoštane džepove i zahvaćenost furkacije (39), a kako je točnost u našoj studiji bila 0,96, može se zaključiti da CBCT može producirati pouzdanu i preciznu sliku kod pacijenata s generaliziranim parodontitisom te je izvrsno pomoćno dijagnostičko sredstvo u planiranju parodontnog liječenja, što je u skladu s nalazima drugih autora $(28,29,34,40,41)$. Studije Waltera i Qiao pokazale su da je $84 \%$ i 82,4\% mjerenja CBCT-om potvrđeno intraoperativnim nalazima u procjeni zahvaćenosti furkacije maksilarnih molara (38\%). Razlike se mogu objasniti kirurškim protokolom koji vjerojatno dovodi do manjeg gubitka parodontnih tkiva tijekom instrumentacije i zbog toga smo mjerenja obavili prije struganja i poliranja korijena. CBCT analiza provedena je samo na defektima tvrdoga tkiva, a intraoperativna mjerenja nisu uključivala debljinu režnja u području furkacije. Istodobno, parodontno sondiranje horizontalne komponente otvorenosti furkacije FI bilo je mjerenje suprakrestalno pričvrsnog tkiva. Zbog toga različite metode mjerenja mogu objasniti nižu povezanost kliničkih $\mathrm{i}$ intraoperativnih ili CBCT mjerenja. Drugo objašnjenje za pogreške koje se pojavljuju između CBCT-a i izravnih kirur- 
that the additional CBCT provided not only detailed information of FI but also facilitated a clear decision for additional periodontal treatment, when compared to treatment recommendations from clinical findings and 2D (periapical) imaging (34). Furthermore, CBCT allows a reduction in treatment costs and time for periodontally compromised maxillary molars (14). Although the full-mouth radiographic series are considered to be current standard in a periodontal diagnostics, especially due to their orthoradial projection, in our study we compared the orthopantomograms since they were already present as part of first examination of the patients. Additional patient irradiation with both CBCT and full-mouth radiograph was not performed due to ethical issues. Orthopantomogram is often already available since it is performed as part of general dental screening of patients. Furthermore, there is the lack of studies that examined orthopantomograms in a comprehensive periodontal diagnostics. The application of CBCT as a promising tool with superior image quality is growing rapidly in dentistry including periodontology. Although it is considered a valuable addition to periodontal clinical assessment, CBCT is not without shortcomings and limitations. Noise, scatter, patients related artefacts, partial volume averaging and beam hardening artefacts (cupping and streak artefacts) could compromise its diagnostic quality, especially for patients with heavy metallic restorations, orthodontic appliances, multiple endodontic treatment or implants $(29,43)$. Its effective radiation dose is still 1,8 times higher than in conventional panoramic radiography and it exposes the sensitive tissues in head and neck region to radiation $(29,44)$. Since the dose varies depending on the device, the field of view and factors of the selected technique, a dose should be reduced by using smaller volume in the region of interest consistent with clinical indications (29). The clinical examination and conventional 2D imaging should continue to be used as routine examination in periodontal assessment. At this time, a routine use of CBCT for the diagnosis and treatment of moderate-to-severe periodontitis does not appear to be warranted from radiation exposure and cost perspective (45). However, in selective cases a limited view of CBCT may be useful and should be considered as an adjunctive diagnostic method after a comprehensive periodontal examination as a useful and widely available tool that has the potential to improve today's standard of care by providing some significant changes in the course of treatment $(23,45)$. For complicated cases when standard examination fails to provide sufficient information for diagnosis and/or treatment planning, CBCT may be added with the smallest available field of view and optimally selected exposure settings (41).

\section{Conclusion}

Our study suggests that different clinical and radiological modalities show a correlation among each other. They are satisfyingly accurate and have benefits, which makes them useful in establishing periodontal diagnosis and aid in treatment planning. However, CBCT offers significant advantages including excellent agreement and higher accuracy; therefore, ških mjerenja jest različita točnost tih mjerenja. Klinička mjerenja mogla su se obaviti na najbližih $0,5 \mathrm{~mm}$, a CBCT mjerenja mogu se obaviti na najbližih $0,1 \mathrm{~mm}$. Walter sugerira da dodatni CBCT nije dao samo detaljne informacije o zahvaćenosti furkacije, nego je omogućio i jasnu odluku za dodatno parodontno liječenje u usporedbi s preporukama za liječenje iz kliničkih nalaza i 2D (periapikalnog) snimanja (34). Nadalje, CBCT omogućuje smanjenje troškova liječenja i vremena za parodontno kompromitirane maksilarne molare (14). Iako se radiografske serije snimki svih zuba (statusi) smatraju trenutačnim standardom u parodontnoj dijagnostici, posebno zbog njihove ortoradijalne projekcije, u našem smo istraživanju uspoređivali ortopatantomograme jer su oni već bili dio prvog pregleda pacijenata. Dodatno ozračivanje pacijenata i CBCT-om i radiogramima zuba nije učinjeno iz etičkih razloga. Ortopantomogram je često već dostupan s obzirom na to da se obavlja kao dio općega stomatološkog pregleda pacijenata, a uz to nedostaje studija u kojima se pregledavao ortopantomogram u sveobuhvatnoj parodontnoj dijagnostici. Primjena CBCT-a, kao obećavajućeg alata vrhunske kvalitete slike, brzo raste u stomatologiji, uključujući i parodontologiju. Iako se smatra vrijednim dodatkom u parodontnoj kliničkoj procjeni, CBCT nije bez nedostataka i ograničenja. Artefakti povezani s "bukom", rasipanjem, djelomičnim prosjekom volumena i artefaktima stvrdnjavanja snopa (artefakti presjeka i pruga), mogu ugroziti njegovu dijagnostičku kvalitetu, posebno kod pacijenata $s$ velikim metalnim restauracijama, ortodontskim aparatima, endodontskim liječenjima ili implantatima $(29,43)$. Njegova efektivna doza zračenja i dalje je 1,8 puta veća negoli u konvencionalnoj panoramskoj radiografiji i izlaže osjetljiva tkiva u predjelu glave i vrata radijaciji $(29,44)$. Budući da doza varira ovisno o uređaju, vidnom polju i čimbenicima odabrane tehnike, treba je smanjiti primjenom manjeg volumena u području interesa u skladu $s$ kliničkom indikacijom (29). Klinički pregled i konvencionalno 2D snimanje i dalje treba primjenjivati kao rutinsku metodu pregleda u parodontologiji. Trenutačno se čini da rutinska uporaba CBCT-a u dijagnozi i liječenju parodontitisa od umjerenog do teškog stupnja nije opravdana zbog visoke doze zračenja i velikih troškova (45). No u pojedinim slučajevima CBCT može biti koristan i treba ga smatrati dodatnom dijagnostičkom metodom nakon sveobuhvatnog parodontnog pregleda jer je koristan i široko dostupan alat koji ima potencijal da poboljša današnji standard njege pružanjem važnih promjena u tijeku tretmana $(23,45)$. Za komplicirane slučajeve, kada standardni pregled ne daje dovoljno informacija za planiranje dijagnoze i/ili liječenja, CBCT se može dodati s najmanjim raspoloživim vidnim poljem i optimalno odabranim postavkama izloženosti (41).

\section{Zaključak}

Naša studija sugerira da različiti klinički i radiološki modaliteti pokazuju uzajamnu korelaciju, da su zadovoljavajuće precizni i da pokazuju dobrobiti, što ih čini važnim u uspostavljanju parodontne dijagnoze i planiranju liječenja. CBCT ima značajne prednosti, uključujući odličnu podudarnost i veću preciznost, te se može koristiti kao opravdano i izvrsno 
it can be used as justified and excellent diagnostic tool in detecting and locating FI and a reliable basis for treatment decisions. Its application should be considered carefully through precise indication in relation to its limitations and risks.

\section{Conflict of Interest.}

None declared. dijagnostičko sredstvo za otkrivanje i lokaliziranje zahvaćenosti furkacije i pouzdan temelj za donošenje odluke o liječenju. Njegovu primjenu treba pozorno razmotriti na temelju postavljanja indikacije s obzirom na njegova ograničenja i rizike.

\section{Sukob interesa}

Autori nisu bili u sukobu interesa.

\section{Sažetak}

Cilj: Željelo se usporediti kliničke, intraoperativne, 2D (panoramske) i 3D (CBCT) parametre u procjeni zahvaćenosti furkacija (Fl-ja). Materijali i metode: $U$ studiju je bilo uključeno šest pacijenata s generaliziranim parodontitisom od II. do IV. stadija B i C razreda, određenih za parodontnu kiruršku terapiju. Ukupno je analizirano 38 molara s 93 furkacije. Svi ispitanici bili su na temeljitom parodontološkom pregledu koji je uključivao procjenu zahvaćenosti furkacije s pomoću Nabersove sonde prema modificiranoj Glickmanovoj klasifikaciji. Parodontna kirurška terapija primijenjena je u slučaju pacijenata s najmanje jednim maksilarnim molarom dubine sondiranja $\geq 6 \mathrm{~mm}$. Rezultati: Sondiranje je pokazalo niži stupanj zahvaćenosti furkacije u usporedbi s intraoperativnim nalazima. Parodontalno sondiranje, intraoperativna mjerenja i mjerenja temeljena na CBCT-u značajno su korelirala jedna s drugima, s r vrijednostima u rasponu od 0,81 do $1,00(p<0,01)$. Korelacija ortopantomograma s parodontnim sondiranjem iznosila je 0,49 , s CBCT-om 0,39 i intraoperativnim mjerenjima 0,36 . Rezultati su pokazali izvrsnu podudarnost i veću preciznost intraoperativnih mjerenja i CBCT-a $(0,96)$, za razliku od kliničkog pregleda i panoramske radiografije $(0,87$ i 0,63). Zaključak: Različiti klinički i radiološki modaliteti pokazuju uzajamnu povezanost, točni su i imaju značajnu kliničku primjenu, što in čini korisnima u postavljanju parodontološke dijagnoze i planiranju liječenja. No CBCT ima znatne prednosti, uključujući i odličnu podudarnost i veću preciznost te se može primijeniti kao klinički opravdano i izvrsno dijagnostičko sredstvo za otkrivanje i lokaliziranje otvorenosti furkacije kako bi se omogućila pouzdana dijagnoza i dobra osnova za donošenje odluke o liječenju.
Zaprimljen: 23. lipnja 2019. Prihvaćen: 15. studeni 2019.

Adresa za dopisivanje Sanja Komšić, doktor dentalne medicine

Ordinacija dentalne medicine Michael Wolf i kolege

Patrickstrasse 2, 65191 Wiesbaden, Njemačka komsic.sanja@gmail.com

\section{Ključne riječi}

defekti račvališta višekorijenskih zubi; kutnjak; parodontitis, parodontno sondiranje

\section{References}

1. Glossary of Periodontal Terms [database on the Internet]. American Academy of Periodontology (Chicago, LA, USA); 2001 [cited 2019 May 25]. Available from: https://members.perio.org/libraries/glossary.

2. Tolentino PHMP, Rodrigues LG, de Torres ÉM, Franco A, Silva RF. Tooth Extractions in Patients with Periodontal Diseases and Clinical Decision-Making Process. Acta Stomatol Croat. 2019 Jun;53(2):141-149.

3. Carnevale G, Pontoriero R, Lindhe J. Treatment of furcation - in volved teeth. In: Lindhe J, Lang NP, Karring T - editors. Clinical Periodontology and Implant Dentistry. Vol 2. 5th ed. Munksgaard; Copenhagen, Denmark: 2012. p. 823-47.

4. McGuire MK, Nunn ME. Prognosis versus actual outcome. III. The effectiveness of clinical parameters in accurately predicting tooth survival. J Periodontol. 1996 Jul;67(7):666-74.

5. Pilloni A, Rojas MA. Furcation Involvement Classification: A Comprehensive Review and a New System Proposal. Dent J (Basel). 2018;6(3):34.

6. Bower RC. Furcation morphology relative to periodontal treatment. Furcation entrance architecture. J Periodontol. 1979 Jan;50(1):23-7.

7. Matia JI, Bissada NF, Maybury JE, Ricchetti P. Efficiency of scaling of the molar furcation area with and without surgical access. Int J Periodontics Restorative Dent. 1986;6(6):24-35.

8. Fleischer HC, Mellonig JT, Brayer WK, Gray JL, Barnett JD. Scaling and root planing efficacy in multirooted teeth. J Periodontol. 1989 Jul;60(7):402-9.

9. DeSanctis M, Murphy KG. The role of resective periodontal surgery in the treatment of furcation defects. Periodontol 2000. 2000 Feb;22:154-68.

10. Al-Shammari KF, Kazor CE, Wang HL. Molar root anatomy and management of furcation defects. J Clin Periodontol. 2001 Aug;28(8):730-40.

11. Hempton T, Leone C. A review of root resective therapy as a treatment option for maxillary molars. J Am Dent Assoc. 1997 Apr;128(4):449-55.

12. Muller HP, Eger T. Furcation diagnosis. J Clin Periodontol. 1999 Aug;26(8):485-98.

13. Walter C, Weiger R, Zitzmann NU. Periodontal surgery in furcationinvolved maxillary molars revisited--an introduction of guidelines for comprehensive treatment. Clin Oral Investig. 2011 Feb;15(1):9-20.
14. Walter C, Weiger R, Dietrich T, Lang NP, Zitzmann NU. Does threedimensional imaging offer a financial benefit for treating maxillary molars with furcation involvement? A pilot clinical case series. Clin Oral Implants Res. 2012 Mar;23(3):351-8.

15. Glickman I. Clinical Periodontology: Prevention, Diagnosis, and Treatment of Periodontal Disease in the Practice of General Dentistry. 4th ed. Philadelphia: Saunders; 1972. pp. 242-5.

16. Aljehani YA. Diagnostic Applications of Cone-Beam CT for Periodontal Diseases. Int J Dent. 2014;2014:865079.

17. Meqa K, Dragidella F, Disha M, Sllamniku-Dalipi Z. The Association between Periodontal Disease and Preterm Low Birthweight in Kosovo. Acta Stomatol Croat. 2017 Mar;51(1):33-40.

18. Acar B, Kamburoğlu K. Use of cone beam computed tomography in periodontology. World J Radiol. 2014 May 28;6(5):139-47.

19. Misch KA, Yi ES, Sarment DP. Accuracy of cone beam computed tomography for periodontal defect measurements. J Periodontol. 2006 Jul;77(7):1261-6.

20. Mol A, Balasundaram A. In vitro cone beam computed tomography imaging of periodontal bone. Dentomaxillofac Radiol. 2008 Sep;37(6):319-24.

21. Banodkar AB, Gaikwad RP, Gunjikar TU, Lobo TA. Evaluation of accuracy of cone beam computed tomography for measurement of periodontal defects: A clinical study. J Indian Soc Periodontol. 2015 May-Jun;19(3):285-9.

22. Woelber JP, Fleiner J, Rau J, Ratka-Krüger P, Hannig C. Accuracy and Usefulness of $C B C T$ in Periodontology: A Systematic Review of the Literature. Int J Periodontics Restorative Dent. 2018;38(2):289-97.

23. McAllister B, Eshraghi T. Cone-Beam Computed Tomography: An Essential Technology for Management of Complex Periodontal and Implant Cases. J Periodontol. 2017 Oct;88(10):937-938.

24. Walter C, Weiger R, Zitzmann NU. Accuracy of three-dimensional imaging in assessing maxillary molar furcation involvement. J Clin Periodontol. 2010 May;37(5):436-41.

25. Qiao J, Wang S, Duan J, Zhang Y, Qiu Y, Sun C, et al. The accuracy of cone-beam computed tomography in assessing maxillary molar furcation involvement. J Clin Periodontol. 2014 Mar;41(3):269-74.

26. Knowles JW, Burgett FG, Nissle RR, Shick RA, Morrison EC, Ramfjord SP. Results of periodontal treatment related to pocket depth and attachment level. Eight years. J Periodontol. 1979 May;50(5):225-33. 
27. Altman DG. Practical Statistics for Medical Research. London: Chapman \& Hall;1991. p. 403-409.

28. Darby I, Sanelli M, Shan S, Silver J, Singh A, Soedjono M, et al. Comparison of clinical and cone beam computed tomography measurements to diagnose furcation involvement. Int J Dent Hyg. 2015 Nov;13(4):241-5.

29. Qiao J, Wang S, Duan J, Zhang Y, Qiu Y, Sun C, et al. The accuracy of cone-beam computed tomography in assessing maxillary molar furcation involvement. J Clin Periodontol. 2014;41(3):269-74.

30. Mol A. Imaging methods in periodontology. Periodontol 2000. 2004;34:34-48.

31. Laky M, Majdalani S, Kapferer I, Frantal S, Gahleitner A, Moritz A, et al. Periodontal probing of dental furcations compared with diagnosis by low-dose computed tomography: a case series. J Periodontol. 2013 Dec;84(12):1740-6.

32. Moriarty JD, Hutchens LH Jr, Scheitler LE. Histological evaluation of periodontal probe penetration in untreated facial molar furcations. J Clin Periodontol. 1989 Jan;16(1):21-6.

33. Graetz C, Plaumann A, Wiebe JF, Springer C, Sälzer S, Dörfer CE. Periodontal probing versus radiographs for the diagnosis of furcation involvement. J Periodontol. 2014 Oct;85(10):1371-9.

34. Walter C, Kaner D, Berndt DC, Weiger R, Zitzmann NU. Three-dimensional imaging as a pre-operative tool in decision making for furcation surgery. J Clin Periodontol. 2009 Mar;36(3):250-7.

35. Brägger U. Radiographic parameters: biological significance and clinical use. Periodontol 2000. 2005;39:73-90.

36. Rotstein I, Simon JH. Diagnosis, prognosis and decision-making in the treatment of combined periodontal-endodontic lesions. Periodontol 2000. 2004;34:165-203.

37. Vandenberghe B, Jacobs R, Yang J. Detection of periodontal bone loss using digital intraoral and cone beam computed tomography images: an in vitro assessment of bony and/or infrabony defects. Dentomaxillofac Radiol. 2008 Jul;37(5):252-60.

38. Hishikawa T, Izumi M, Naitoh M, Furukawa M, Yoshinari N, Kawase $\mathrm{H}$, et al. The effect of horizontal X-ray beam angulation on the detection of furcation defects of mandibular first molars in intraoral radiography. Dentomaxillofac Radiol. 2010 Feb;39(2):85-90.

39. du Bois AH, Kardachi B, Bartold PM. Is there a role for the use of volumetric cone beam computed tomography in periodontics? Aust Dent J. 2012 Mar;57 Suppl 1:103-8.

40. Cimbaljevic MM, Spin-Neto RR, Miletic VJ, Jankovic SM, Aleksic ZM, Nikolic-Jakoba NS. Clinical and CBCT-based diagnosis of furcation involvement in patients with severe periodontitis. Quintessence Int. 2015 Nov-Dec;46(10):863-70.

41. Zhang W, Foss K, Wang BY. A retrospective study on molar furcation assessment via clinical detection, intraoral radiography and cone beam computed tomography. BMC Oral Health. 2018 May $3 ; 18(1): 75$.

42. Walter C, Weiger R, Zitzmann NU. Accuracy of three-dimensional imaging in assessing maxillary molar furcation involvement. J Clin Periodontol. 2010 May;37(5):436-41.

43. Schulze R, Heil U, Gross D, Bruellmann DD, Dranischnikow E, Schwanecke U, et al. Artefacts in CBCT: a review. Dentomaxillofac Radiol. 2011 Jul;40(5):265-73.

44. Batista WO, Navarro MV, Maia AF. Effective doses in panoramic images from conventional and CBCT equipment. Radiat Prot Dosimetry. 2012;151(1):67-75.

45. Kim DM, Bassir SH. When Is Cone-Beam Computed Tomography Imaging Appropriate for Diagnostic Inquiry in the Management of Inflammatory Periodontitis? An American Academy of Periodontology Best Evidence Review. J Periodontol. 2017 Oct;88(10):978998. 